\title{
The Perception and Views of Photographers on Artistic Photography in Turkey
}

\author{
Hakan Yaman \\ Independent Scholar, Konyaalt1-Antalya, Turkey \\ Received: December 13, 2017. Revised: April 23, 2018. Accepted: June 10, 2018
}

\begin{abstract}
The purposes of this study are to know generally the perception and view of photographers on artistic photography in a purposeful sample in Turkey. Participants were purposefully selected (purposive sample) from the community of photographers because it would represent diverse photographers in Turkey. The survey included 19 questions and divided into three parts. Findings of our study revealed that most of the participants were at their middle-age, male, married, university graduates, private sector employed, DSLR users, amateur/ traveling-landscape-portrait photographers, and they shoot their photos to be happy, to document anything, and for spending time (Hobby). They mainly thought that photos should be taken for documentary reasons. The creativity is mainly dependent on perspective (or photographic seeing). Good photography could be achieved with good photographic technique, a good photo is relying on the influence to the spectator, photo critics/reading should be mainly based on technique, the most influential movement is realism, artistic photography will improve, photography in future will improve, and some are participating in photographic projects. The results show that good grounds exist in Turkey to shape artistic photography for the needs of the 21st century.
\end{abstract}

Keywords: Photography; Leisure; Hobby; Art; Turkey

How to Cite: Yaman, H. (2018). The Perception and Views of Photographers on Artistic Photography in Turkey. Harmonia: Journal of Arts Research And Education, 18(1), 74-81. doi:http:/ / dx.doi.org/10.15294/harmonia.v18i1.14667

\section{INTRODUCTION}

Photography is a scientific subject with a multi-disciplinary orientation. Photography has also benefitted from innovation and technological development. Not only the way we see photography, but also the involvement of people has changed. Nowadays everybody is taking photos, and the dissemination of these media is globally overwhelming. People are exposed every day to various images, and a search visual literacy seems to be needed more than any time before (Nicholls, 2015).
Photography is now very popular. Cameras are easily accessible and if not everybody has a smartphone with an inbuilt camera. People are documenting every personal moment and share these on every occasion. There are also other people, who spend their free time with photography. They study, work, devote themselves, create, produce, share, document their photographic involvement ( $\mathrm{Lim}, 2017)$. It is also the case for Turkey. Almost every province in Turkey, with at least one photographic society/club which brings together photographers, organizes contests, photo marathons, publishes periodicals and books. Major universities

\footnotetext{
Corresponding author: Uncalı Mh. 1262. Sk. No: 15, Öksüzoğlu Konakları, Antalya-Türkiye

E-mail: hakanyam@yahoo.com
} 
have departments of photography with stateof-art curricula.

The frequency and numbers of activities in Turkey are overwhelming, but documentation on these photographers is missing. Therefore, we were interested to know generally the perception and view of photographers on artistic photography in a purposeful sample in Turkey.

\section{METHOD}

Photographers living in different cities were asked to participate in this study in December 2017. Eighty-five photographers agreed and gave verbal consent to participate. Participants were purposefully selected (purposive sample) from the community of photographers because it represent diverse photographers in Turkey.

The survey included 19 questions and divided into three parts. The first part included questions on demographics and possession of a photo-camera. The second part included questions about experience and membership in photography, and finally, the third part asked questions about their thoughts concerning photography. The survey was piloted with six photographers, and the results of the pilot questionnaire were not included in the final dataset.

Open-ended questions were analyzed by $\mathrm{AY}$ and $\mathrm{ZK}$ for content. Answers were classified into common subject headings, which arose from the answers. Subject headings were compared after separate analysis and were compiled afterward to one form. Informed consent was obtained from all individual participants included in the study.

Data were analyzed with descriptive statistics. The level of significance was set at alpha $=0.05$.

\section{RESULT AND DISCUSSION}

\section{Result of data analysis}

Events and festivities covering photography are steadily increasing in Turkey. Photography as an academic discipline is well established as are the diverse photo- graphy societies in Turkey. Information on photographers dealing with their perception and views concerning artistic photography were missing in Turkey and no similar studies were available in the literature. We therefore retrieved the following results from our study, which we would like to share: Eightyfive photographers participated in this study.

Their mean age was $40.3(\mathrm{SD}=13.31$; range $=1-68) ; 22(37 \%)$ were female and 38 $(63 \%)$ were male; 32 (39\%) were single, 44 (53\%) were married, and 7(8\%) divorced/ widowed. Seven $(8 \%)$ graduated from high school, 59 (71\%) from university, and 17 (21\%) from postgraduate programs (Master/ $\mathrm{PhD})$. Twenty eight $(35 \%)$ were employed in public sector, $35(43 \%)$ in private sector, and $18(22 \%)$ were students. The mean photography experience was 10.8 years $(\mathrm{SD}=$ 11.20 ; range $=1-54)$. Sixty six $(79 \%)$ participants defined themselves as an amateur, nine $(11 \%)$ as a professional, and $8(10 \%)$ neither amateur nor professional photographers.

Affiliation to local photography societies was relatively high. Fourteen (17\%) stated to be a member of ANFAD (Antalya Photographers and Amateur Cinema Lovers Society, Turkey), 12 (14\%) of ANFOK (Antalya Photography Club, Turkey), 14 (17\%) of Sille Sanat Saray1 (ILFIAP, Konya, Turkey), $30(35 \%)$ of other societies/clubs in Turkey.

The preference of style of photography of participants is displayed in Table 1. The search for a personal style is like looking for the "holy grail" among photographers. It is a non-ending evolutional process, which is affected by diverse factors. These could be based on the subject chosen, on the technique the photographers uses, the methods after shooting (postproduction), or any combination of these (Quist, 2017). Or could be related to three points: does the style fit the subject matter the photographer has chosen? Does it fit to the personality of the photographer? Does it enhance the photo? If the changes are appropriate to the subject chosen, it fits to your personality, and the styled applied dos improve the photo then the photographer is on its right way (Steadman, 2013). But beyond personal issues there are 
different styles (genres) defined in literatures. Even a consensus in the definition of these genres are lacking, we can speak of different styles ranging from 32 to 50 (Urby, 2018; Webneel.com, n.d.). In this study 15 different styles have been mentioned. Travelling, landscape, and portrait were the most frequent ones mentioned.

Table 1. The preference of style of photogra-

\begin{tabular}{ccc} 
phy & $\mathrm{n}$ & $\%$ \\
\hline Style of Photography & 45 & 53 \\
Portrait & 62 & 73 \\
Traveling & 55 & 65 \\
Landscape & 39 & 46 \\
Street & 5 & 6 \\
Fashion & 23 & 27 \\
Architecture & 7 & 8 \\
Wedding & 17 & 20 \\
Documentary & 5 & 6 \\
Journalism & 9 & 11 \\
Other (i.e. nature, product, indus- \\
trial, light-art etc.) & & \\
\hline
\end{tabular}

Eight (9\%) had an Analog Camera, 53(62\%) a Digital Camera, 12(14\%) a Mirrorless Digital Camera, 34(40\%) Smart Phone Camera, and $1(1 \%)$ a Drone Camera.

The reason for taking/shooting photos is shown in Table 2. Different papers and personal impressions are reporting on reasons for taking/shooting photos. Most frequent reasons stated are recording important events and memories (Pryor, 2013; Poster, 2011). If you enlarge the reasons of taking/shooting photos then we could enlarge the reasons to more items (i.e. recording memories, having fun, nurturing the brain, promoting health and fitness, enhancing creativity, reason for travel, networking, join a photographic society, developing personal style etc.) (Hill, 2017). The answers retrieved in our study showed similar results. The answer "for happiness" could be accepted as "for fun". Looking at the profile of the respondents of this study, the majority defined themselves as amateurs. Therefore the majority can be expected to shoot photos to become happy. Another interesting answer was "assignment". The reason for this answer were students, who participated in this study and had to deliver photography assignments to the university faculty.

Table 2. Reasons for Taking/Shooting Photos

\begin{tabular}{ccc}
\hline Reasons of Taking/Shooting Photos & $\mathrm{n}$ & $\%$ \\
\hline Free Time/Hobby & 22 & 26 \\
For happiness & 62 & 73 \\
Assignment & 4 & 5 \\
Earn for existence & 10 & 12 \\
For documentation & 36 & 42 \\
To get famous & 1 & 1 \\
Other (i.e. memoir, express feelings, & 9 & 11 \\
therapy etc.) & & \\
\hline
\end{tabular}

Replies to open-ended questions are given below:

Question: Why should we take photos?

Answer:

To register/document the moment $(\mathrm{n}=35)$.

To display different cultures of seeing $(\mathrm{n}=3)$.

To relax, to be happy, to enjoy $(n=10)$.

Interest, curiosity $(\mathrm{n}=1)$.

Hobby, spend good time $(\mathrm{n}=9)$.

To express feelings $(n=5)$.

Awareness $(\mathrm{n}=1)$.

To communicate $(\mathrm{n}=1)$.

To share $(n=1)$.

In addition to the closed-ended question above, which answers are enlisted in Table 2, this findings add some further aspects of taking/shooting photos. Photography enables the person to develop and grow themselves by adding value to their lives. Their experience was easily shared in a meaningful ways via photos (Hill, 2017; Quora, 2017; Shulman, 2014).

Question: What is determining creativity in photography?

Answer:

Being able to see feelings in photos $(n=3)$. Perspective $(\mathrm{n}=17)$.

To deal differently with the subject $(\mathrm{n}=3)$.

Knowledge on art and aesthetics $(\mathrm{n}=8)$.

Experience $(\mathrm{n}=2)$. 
Phantasy, imagination $(\mathrm{n}=9)$.

Eye of photography $(n=5)$.

Processing the photo $(n=1)$.

Visual intelligence $(n=1)$.

Maturity ( $n=4)$.

Reflecting the inner world outside $(n=2)$.

Creativity is a capability, which could be supported by constantly learning. Practice is mentioned the key for improving creativity in photography. Following successful masters in photographers is another way for improvement. A creative photographer is a lucky person, who successes to shoot good photos of common subjects. The photos are expected to tell a story, which have an important impact on the person. Therefore developing a personal style is a prerequisite for creativity. Having all these skills and conditions and some luck (i.e. right time, right place, etc.) will support creativity and success in photography (Hollenbeck, 2014).

Question: How can we shoot a good photo?

Answer:

Good photo-technique $(\mathrm{n}=34)$.

Good equipment $(n=5)$.

Good observation $(n=2)$.

Depends on money, place, and time $(n=1)$.

Appropriate training $(n=4)$.

Experience $(n=4)$.

Phantasy $(n=1)$.

Is more subjective $(n=5)$.

Based on feelings $(n=5)$.

Strong expressions $(n=3)$.

The responses of the participants are in congruence with the sources available in the internet (Clarke, 2014; Mansurov, 2018).

Question: What is a good photo?

Answer:

Influencing the spectator/visitor $(\mathrm{n}=15)$.

Displayed in an aesthetic way $(\mathrm{n}=5)$.

Substantial meaning $(\mathrm{n}=11)$.

Substantial artistic meaning $(\mathrm{n}=1)$.

Substantial perspective $(n=1)$.

Best storytelling $(\mathrm{n}=2)$.

Technically best shoot $(n=14)$.

Originality $(\mathrm{n}=1)$.

Unforgettable, enviable $(n=1)$.
A good photo is expected to deliver a clear vision, to harmonize with the spectator's vision and suits the spectator's tastes (Cox, 2018). Our findings support this statement.

Question: What should consider during photo readings/critics?

Answer:

Photo techniques $(\mathrm{n}=33)$.

Success in depiction $(n=13)$.

Its story $(\mathrm{n}=1)$.

Artistic perspective $(n=3)$.

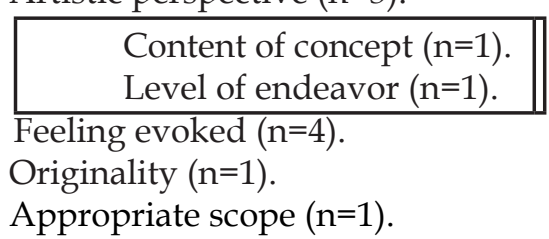

Guidelines on reading photos expect the understanding the three-dimensional environment (i.e. culture, visual elements, icons, and symbols) of photography. Working out subject matter, form, medium, and context will help to understand the content of a photo (Oosterhoff, 2015).

Question: Which photo movements are influencing you at most?

Answer:

Environmental photography movement $(\mathrm{n}=3)$

Photojournalism photography movement $(\mathrm{n}=3)$.

Surrealism photography movement $(\mathrm{n}=4)$.

Impressionism photography movement $(\mathrm{n}=3)$.

Documentary photography movement $(\mathrm{n}=4)$.

Realism photography movement $(\mathrm{n}=5)$.

Post impressionism photography movement $(\mathrm{n}=1)$.

Naturalistic photography movement $(\mathrm{n}=2)$.

Symbolism photography movement $(\mathrm{n}=1)$.

Romanticism photography movement $(\mathrm{n}=2)$.

This question gives a clue on the knowledge of participants on the history of photography and movements. 
Question: At what degree do you see artistic photography?

Answer:

It is a highest level $(n=7)$.

Artistic photography will improve $(n=13)$.

It is not at expected level $(n=10)$.

It is an art, like painting $(n=2)$.

Its technique end aesthetics is improving $(\mathrm{n}=1)$.

Is declining $(n=5)$.

It is not an independent art $(n=1)$.

Now everybody is a photographer $(n=5)$. Everybody has a smart-phone camera $(n=5)$.

Arrogance, egoism, money $(\mathrm{n}=1)$.

It is real and is documentation $(n=1)$.

The perfect photo is unreachable $(n=1)$.

It is an art, which is decaying in the virtual prison $(n=1)$.

Different definitions of artistic photography are available. "Art photography" is photography, which is done as a fine art. Whereas "Artistic photography" is more the aim to convey a personal impression on the photographic work ( Fine-art photography, 2018). The respondents have a more positive view concerning the improvement of artistic photography.

Question: how do you perceive the future of photography?

Answer:

It will improve $(\mathrm{n}=11)$.

It has a good future $(n=5)$.

As long as life endures, photography will persist $(\mathrm{n}=2)$.

Video will replace photography $(n=3)$.

Cameras will improve technically $(n=5)$.

Everybody will get involved with photography $(n=3)$.

Documentary photography will increase $(\mathrm{n}=1)$.

It will detach from reality $(\mathrm{n}=1)$.

Individualism will increase $(\mathrm{n}=1)$.

It will improve as a separate art $(n=1)$.

Photography as a way of art will develop $(\mathrm{n}=1)$.

With increasing technology, it will lose its artistic orientation $(n=1)$.

Looking at futuristic assumptions important changes will occur, which are also partially mentioned by the participants of this study. These changes are estimated as the development of stronger sensors, smaller cameras, intelligent cameras, versatile lenses, alternative energy solutions, new formats, smarter software, and closer integration to human body (Zhang, 2017). Artificial Intelligence and constant connectivity will be further enhancements in future photography (Davis, 2017; (Matusek, 2017; (Raza, n.d.)

Question: Are you involved in photographic projects?

Answer:

Travel photography $(\mathrm{n}=6)$.

Documentary photography $(\mathrm{n}=2)$.

ExLibris $(\mathrm{n}=1)$.

\section{Discussion}

Art is elementary for each society. People especially have an inborn aesthetic sense, which helps to create social meaning and values in a human being. Art helps the community to find itself and its own identity. It enables us to build up self-awareness and forms an understanding to other people. It is a way of personal enrichment and improvement (Coles, 2018). But, there are challenges. Everybody thinks, that they are in command of a foreign language, the photography.

Billions of people are taking photos and might consider themselves as amateur photographers. Trillions of photos are circulating around the globe. The digital revolution made the production of photos easier, but a confusion in photography evolved, due to the mass of photos created. The invention of new ways of photographic education and training is certainly an answer to this confusion (Nicholls, 2015). The existence of photographic societies and clubs will certainly help to overcome this challenge. A well-established network of societies and clubs, like in Turkey, with the support of academia are an important prerequisite for this.

The increase of photos should not be a reason for concern. People are like the sufferers in Plato's cave, who just see the ideas falling on the wall. Only their personal evolution will hopefully enable them to see the real image. And, this search might be enabled by 
practice, thoughts, and taking plenty of photography (Sontag, 1977; 2017).

There have been made different consideration on photography. Trying to understand this phenomenon, classifications have been made. These were external and were empirical (Professionals/ Amateurs), rhetorical (Landscapes/Objects/Portraits/ Nudes), or aesthetic (Realism/Pictorialism); but some mean these classifications are not touching its essence and that photography cannot be classified (Barthes, 2003).

Beside these concerns we had to classify our participants and found that most were at their middle-age, male, married, university graduates, private sector employed, DSLR users, amateur/ traveling-landscape-portrait photographers, and they shoot their photos to be happy, to document anything, and for spending time (Hobby).

Photography was used as evidence since its early invention. Therefore, the belief that photos are identical to the objects they are photographed, still persists. And people like in our study pretend to say that they shoot photos to register or document anything they have chosen. But looking closer we could differentiate the non-interfering observer from the artist, which is in analogy with seeing and photographic seeing (Sontag, 1977; 2017). This way of seeing will certainly enhance creativity with the support of imagination and knowledge of arts and aesthetics (Huang, 2011).

The term aesthetic is in simple words, the appearance of an object that is pleasing the eye. In photography, different kinds of rules are setting the standard. The judgment of the photo depends on other criteria, too. But the difference between a trained and a lay eye concerning the perception of art might be enormous. The judgment of a trained artist on the beauty of an object depends on technique in photography. The ability of understanding aesthetics and ingenuity in photography can be trained and learned (Jacobitz, 2017). As mentioned by participants good and/or aesthetic photographs could be achieved mainly by good technique, good equipment and creativity.
The visualization and conceptualization of an idea before taking a photo, the imitation of reality, good preparation and post-production, composition (leading lines, golden ratio etc.) might lead to a good photo (Jacobitz, 2017).

Painters since ages were looking for a visual truth and created different movements during their enduring search in art. And photography followed this path as well (de Wolfe, 2018), even the belief of photography as a mechanical record did not fade away. Fox Talbot published the first book illustrated the photographic book, which ne named "The Pencil of Nature". This was a visionary choice, because the camera remained always the pencil of nature (Prodger, 2012).

Today the artistic core of photography is accepted as the capture of the deliberate moment of reality. The ability of the artistic photographer to capture a moment of reality and the transformation of it into an aesthetic/viewable image is accepted as an artistic process (Encyclopedia of Art, 2018).

\section{CONCLUSION}

Findings of our study revealed that most of the participants were at their middleage, male, married, university graduates, private sector employed, DSLR users, amateur/ traveling-landscape-portrait photographers, and they shoot their photos to be happy, to document anything, and for spending time (Hobby). They mainly thought that photos should be taken for documentary reasons, the creativity is mainly dependent on perspective (or photographic seeing), good photography could be achieved with good photographic technique, a good photo is relying on the influence to the spectator, photo critics/reading should be mainly based on technique, the most influential movement is realism, artistic photography will improve, photography in the future will improve, and some are participating in photographic projects. The results show that good grounds exist in Turkey to shape artistic photography for the needs of the $21^{\text {st }}$ century. 


\section{REFERENCES}

Barthes, R. (2003). Extracts from Camera Lucida. In L. Wells (Ed.), The Photography Reader (1st Editio). London.

Clarke, L. (2014). 40 Tips to Take Better Photos. Retrieved August 14, 2018, from https:// petapixel. com/2014/01/24/40-tips-take-better-photos/

Coles, S. M. (2018). The Wisdom of Crowds. Retrieved from http:// www.photopedagogy.com/uploads/5/0/0/9/50097419/photo_ pedagogy_think_piece..pdf.

Cox, S. (2018). What Makes a Good Photo? - Photography Life. Retrieved August 18, 2018, from https://photographylife.com/what-makes-a-goodphoto

Davis, B. (2017). 5 Predictions for the Future of Photography - DigitalRev. Retrieved August 14, 2018, from https://www.digitalrev.com/ article/5-predictions-for-the-futureof-photography

Encyclopedia of Art. (2018). Is Photography Art? In Visual arts cork.com. Retrieved from http://www.visualarts-cork.com/ photography-art.htm

Hill, S. (2017). 10 Reasons Why Photography is a Great Hobby. Retrieved August 2, 2017, from https://digital-photography-school.com/10-reasons-photography-great-hobby/

Hollenbeck, C. (2014). Photographic Ability and Creativity | Educational articles and book excerpts on photography topics. Retrieved August 14, 2018, from https://www.photovideoedu.com/Learn/Articles/photographic-ability-and-creativity.aspx

Huang, Y.-H. (2011). Understanding digital-altered photographs through photographers' views of reality: Matt Siber as an example (p. 282). London: British Computer Society (BCS). Retrieved from https://ewic.bcs.org/ content/ConWebDoc/40564

Jacobitz, S. (2018). Photography Basics: Understanding Aesthetic Photogra- phy. Retrieved August 14, 2018, from https://www.iamlivingit.com/photography/aesthetic-photography

Lim, L. (2017). 54 Reasons Why YOU Should Be A Photographer (+How to Get Into It). Retrieved August 14, 2018, from https://photographyconcentrate.com/54-reasons-whyyou-should-be-photographer/

Mansurov, N. (2018). How to Take Good Pictures - Photography Life. Retrieved August 15, 2018, from https:/ / photographylife.com/howto-take-good-pictures

Matusek, S. (n.d.). 5 Predictions for the Future of Photography - Vantage - Medium. Retrieved August 15, 2018, from https://medium.com/ vantage/5-predictions-for-the-future-of-photography-f95be2cc6689

Nicholls, J. (2015). What is photography? Retrieved May 15, 2018, from https: / / www.photopedagogy. com/what-is-photography.html

Oosterhoff, D. (2015). How to Read a Photograph. Retrieved August 15, 2017, from https://photography.tutsplus. com/tutorials/how-to-read-a-photograph--cms-25495

Poster, G. (2011). 3 Reasons To Take Photos | Life Your Way. Retrieved August 14, 2018, from https://lifeyourway. net/3-reasons-to-take-photos/

Prodger, M. (2012). Photography: is it art? Art and design | The Guardian. Retrieved July 15, 2016, from https://www.theguardian.com/artanddesign/2012/oct/19/ photography-is-it-art

Pryor, J. (2013). Why Do We Take Photos? Retrieved August 17, 2017, from https:/ / www.picturecorrect.com/ tips/why-do-we-take-photos/

Quist, K. (2017). How to Find your Personal Photographic Style. Retrieved August 14, 2017, from https://digital-photography-school.com/howto-find-your-personal-photographic-style/

Quora. (2017). Human Behavior: Why do people take photos? - Quora. 
Retrieved August 17, 2018, from https://www.quora.com/HumanBehavior-Why-do-people-take-photos

Raza, F. (n.d.). 5 Predictions For the Future of Digital Marketing.

Shulman, M. (2014). Why We Take Pictures | HuffPost. Retrieved August 15, 2018, from https://www.huffingtonpost.com/monica-shulman/ why-we-take-pictures_b_6009434. html

Sontag, S. (1977). On Photography. London: The Penguin Group. Retrieved from http:/ / www.susansontag.com/SusanSontag/books/onPhotographyExerpt.shtml

Steadman, A. (2013). How Important is Style in Photography? Retrieved
January 10, 2018, from https:/ / petapixel.com/2013/11/21/importantstyle/

Urby. (2018). Best 32 Types of Photography | Genres of Photography | Photography Styles. Retrieved April 11, 2018, from https://www.urby.in/ blog/types_of_photography/

Webnel.com. (n.d.). 50 Different Types of Photography Styles with examples for your inspiration. Retrieved $\mathrm{Au}-$ gust 13, 2018, from http://webneel. com/different-types-of-photography

Zhang, M. (2017). 10 Predictions About the Future of Photography. Retrieved August 15, 2018, from https://petapixel.com/2017/08/18/10-predictions-future-photography/ 